\title{
Effect of hcpl of the Type VI Secretion System on Biological Characteristics of F18 Shiga Toxin-Producing Escherichia coli
}

\author{
Yang Yang ${ }^{1,2}$, Hong Zhou ${ }^{3}$, Ji Shao ${ }^{1,2}$, Xinyi Zhang ${ }^{1,2}$, Pengpeng Xia ${ }^{1,2}$, \\ Mingxu Zhou, ${ }^{4,5}$, Qiangde Duan ${ }^{1,2}$ and Guoqiang $\mathrm{Zhu}^{1,2 *}$ \\ ${ }^{1}$ College of Veterinary Medicine, Yangzhou University, Yangzhou 225009, China \\ ${ }^{2}$ Jiangsu Co-Innovation Center for Important Animal Infectious Diseases and Zoonoses, \\ Yangzhou 225009, China \\ ${ }^{3}$ School of Basic Medical Science, Southwest Medical University, Luzhou 646000, China \\ ${ }^{4}$ Institute of Veterinary Immunology and Engineering, National Research Center \\ of Engineering and Technology for Veterinary Biologicals, Jiangsu Academy of \\ Agricultural Sciences, Nanjing 210014, China \\ ${ }^{5}$ Jiangsu Key Laboratory for Food Quality and Safety-State Key Laboratory Cultivation \\ Base, Ministry of Science and Technology, Nanjing 210014, China
}

Yang Yang and Hong Zhou contributed equally to this work.

\section{A B S T R A C T}

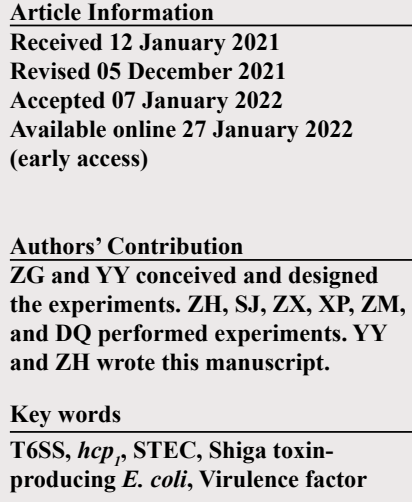

The objective of this study was to investigate the effect of hcp 1, a main structural gene of type VI secretion system (T6SS), on the biological characteristics related to the virulence factor of F18 Shiga
toxin-producing Escherichia coli (STEC). In this study, based on the construct of the wild type F18 STEC (F18), hcpl deletion mutant (F18ab $\triangle h c p l)$ and complement strain (F18ab $\triangle h c p 1 / p h c p 1)$, their pathogenic differences were compared, and the function of $h c p l$ was discussed from the aspects of growth curve, biofilm formation, adherence, invasion, cytotoxicity, and so on. The results showed that hcpl of the T6SS did not influence bacterial growth and biofilm formation. In F18ab $\triangle$ hcpl, bacterial motility, adherence and invasion towards the intestinal porcine enterocyte cells (IPEC-J2) were reduced significantly, and the cytotoxicity decreased. The results of RT-PCR showed that in F18ab $\triangle h c p 1$, the flagella gene $f$ lic and type I fimbriae fimA were significantly down-regulated. In conclusion, $h c p 1$ gene of F18 STEC is related to flagella expression, bacterial adherence, invasion, and secretion of Stx2e toxin. T6SS hcpl is proved to be closely involved in the pathogenesis of F18 STEC.

\section{INTRODUCTION}

$\mathrm{S}$ higa toxin-producing Escherichia coli (STEC) expressing F18 fimbriae is one of important pathogens causing diarrhea and edema in weaned piglets, which has brought huge losses to pig industry in China (Yang et al., 2013). F18 E. coli has many remarkable biological characteristics. It can express F18 fimbriae, type I fimbriae, AIDA and flagella. After adherence and invasion towards pig intestinal epithelial cells, F18 STEC secrete Shiga toxin (Stx2e) and damage pig intestines (Da et al., 2001). These virulence factors are closely related to its pathogenicity, and may be regulated by type VI secretory system (T6SS).

Recently, bacterial secretory systems have become one

\footnotetext{
* Corresponding author: yzgqzhu@yzu.edu.cn 0030-9923/2022/0001-0001 \$ 9.00/0

Copyright 2022 Zoological Society of Pakistan
}

of the frontier research fields of pathogenic microorganisms (Yi et al., 2019). Many studies have found that T6SS plays an important role in bacterial pathogenicity, and mediates interaction between bacteria and environment (Zheng et al., 2011). It has also been found to influence bacterial interspecific competition. T6SS is encoded by a gene cluster containing 15-20 conservative open reading frames (ORFs) with an average length of more than $20 \mathrm{~kb}$. About 25\% Gram-negative bacteria contain T6SS gene cluster (Williams et al., 1996; Pukatzki et al., 2009).

T6SS has been reported to be closely involved with bacterial pathogenicity (Peng et al., 2016). Shrivastava et al. (2008) found that the heme carrier protein (HCP), a heme-regulated protein that was encoded by hcp gene, can form a hexamer ring structure that can participate in the formation of transport channels connecting the inner and outer membrane of bacteria (Filloux et al., 2008). $\mathrm{HCP}$ is involved in the pathogenic process of a variety 
of bacteria. It have been reported to participate in the resistance of Vibrio cholerae and Burkholderia to the predation of Amoeba (Pukatzki et al., 2007; Aubert et al., 2008), in the inhibition of the phagocytosis of Aeromonas by macrophages (Suarez et al., 2008), in the increase of Salmonella survival ability in host cells (Parsons and Heffron, 2005), in the biofilm formation of Vibrio cholera (Yahr, 2006), and in promotion of acute and chronic infection of some pathogens (Yahr, 2006; Filloux et al., 2008; Hood et al., 2010), etc. E. coli contains multiple hcp clusters. Zhou et al. (2012) found that Hcp1 of E. coli could induce cytoskeleton rearrangement, apoptosis, IL-6 and IL-8 release of human brain microvascular endothelial cells. Hcp2 was related to the adherence and invasion of bacteria to host cells. Ding et al. (2018) proved that in avian pathogenic E. coli (APEC), Hcp1 and Hcp2 were jointly involved in biological characteristics such as adherence and viability. Hcp1 affected Quorum sensing, while as Hcp2 participated in biofilm formation. Hu et al. (2021) discovered three $h c p$ gene clusters ( $h c p 1, h c p 2$ and $h c p 3$ ) in porcine extraintestinal pathogenic E. coli. All 3 gene clusters were involved into bacterial pathogenicity and participate in the colonization and persistence of bacteria in the host. Song et al. (2020) discovered that the deletion of hcp $2 a$ in APEC could improve biofilm formation, reduce resistance to chicken serum and suppress the expression of IL8 and IL1 $\beta$ in host cells. It was found that hcp 1 and $h c p 2$ gene clusters also exist in STEC, which may participate in the secretion and assembly of virulence factors and play an important role in bacterial pathogenesis. However, in F18 STEC, exact function of T6SS hcpl and its relationship with bacterial virulence have not been explored clearly.

To further analyze the effect of T6SS hcpl in bacterial virulence, F18ab STEC 107/86 reference strain was selected, and hcpl deletion strain was constructed by $\lambda$ Red-based recombination system. Function of hcpl was further discussed by comparing the differences in growth, biofilm, motility, adherence, Stx2e production between wild type and hcpl deletion strain.

\section{MATERIALS AND METHODS}

Materials and the construction of F18ab $\Delta$ hcp1 and F18ab $\Delta \mathrm{hcp} 1 / \mathrm{phcp} 1$

The strains and plasmids are listed in Table I. F18ab STEC 107/86 was stored in our laboratory (Yang et al., 2014). All strains were grown at $37^{\circ} \mathrm{C}$ in $\mathrm{LB}$ medium with $100 \mu \mathrm{g} / \mathrm{mL}$ Ampicillin (Amp) or $34 \mu \mathrm{g} / \mathrm{mL}$ chloramphenicol $(\mathrm{Cm}+)$ added if requested. The intestinal porcine enterocyte cell line (IPEC-J2) was grown in RPMI 1640-F12 medium supplemented with $10 \%$ neonatal bovine serum $\left(37^{\circ} \mathrm{C}, 5 \% \mathrm{CO}_{2}\right)$. Vero cells were cultured in DMEM medium supplemented with $10 \%$ fetal bovine serum $\left(37^{\circ} \mathrm{C}, 5 \% \mathrm{CO}_{2}\right)$. Plasmids $\mathrm{pKD} 3, \mathrm{pKD} 46$ and pCP20 used for $\lambda$ Red-based recombination system were preserved in our laboratory. 4-week-old ICR mice were purchased from the Institute of Comparative Medicine of Yangzhou University.

The deletion strain F18ab $\Delta h c p 1$ was constructed by $\lambda$ Red-based recombination system using $\triangle h c p 1$ 1) $\Delta h c p 1-2$ primers (Table II) (Datsenko and Wanner, 2000). Construction of the hcpl deletion strain was further verified by DNA sequencing. The ORF of hcpl was amplified by PCR by using Hcp1-1/Hcp1-2 primers (Table II). After insertion of hcpl into pBR322, the complement plasmid pBR-hcpl was constructed. The plasmid was transformed into the deletion strain F18ab $\Delta h c p 1$ for the construction of F18ab $\Delta h c p 1 / \mathrm{p} h c p 1$.

\section{Growth curves, biofilm formation and mobility assays}

The wild type (F18ab), deletion mutant (F18ab $\Delta h c p 1)$

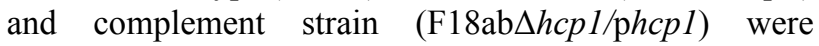
inoculated in LB medium and cultured overnight at 37 ${ }^{\circ} \mathrm{C}$. $\mathrm{OD}_{600}$ of each strain was measured every hour. The experiment was repeated 3 times to obtain the growth curves (Yang et al., 2018, 2021).

\section{Table I. Strains and plasmids used in this study.}

\begin{tabular}{|c|c|c|}
\hline Items & Details & Provider \\
\hline \multicolumn{3}{|l|}{ Strains } \\
\hline E. coli F18ab $107 / 86$ & Wild-type O139:H1:F18ab, Stx2e; O139:H1:F18ab, Stx2e & Kept and provided by our own lab \\
\hline E. coli F18ab $\Delta$ hcp 1 & Hcpl deletion mutant & Constructed in this study \\
\hline E. coli F18ab $\Delta$ hcp1/phcp1 & $\mathrm{F} 18 \mathrm{ab} \Delta f l i C$ carrying $\mathrm{pBR}-h c p 1$ & Constructed in this study \\
\hline \multicolumn{3}{|l|}{ Plasmids } \\
\hline pBR322 & Expression vector, $A_{m p}{ }^{r}$ & Takara Ltd. \\
\hline pKD3 & $\mathrm{Cm}^{\mathrm{r}}$; Cm cassette template & Kept and provided by our own lab \\
\hline $\mathrm{pKD} 46$ & $\mathrm{Amp}^{\mathrm{r}}, \lambda$ Red recombinase expression & Kept and provided by our own lab \\
\hline pCP20 & $\mathrm{Amp}^{\mathrm{r}}, \mathrm{Cm}^{\mathrm{r}}$; Flp recombinase expression & Kept and provided by our own lab \\
\hline
\end{tabular}


Table II. The primers for the Real Time PCR.

\begin{tabular}{|c|c|}
\hline Primer & Sequences (5'-3') \\
\hline hcpl-1 & $\begin{array}{l}\text { 5'-GCCGGATCCATGGCGAATTTAATTTAT- } \\
\text { TTAAC- 3' }\end{array}$ \\
\hline$h c p 1-2$ & $\begin{array}{l}\text { 5'-TAAAGTCGATTAAAAAAGACGATCT- } \\
\text { TCCC-3' }\end{array}$ \\
\hline$\Delta h c p 1-1$ & $\begin{array}{l}\text { 5'-ATGCTCCCATATAATTGACTCATAACT- } \\
\text { GAAAGAAACTGACTCTTCGGGTTGTG- } \\
\text { TAGGCTGGGAGCTGCTTC-3' }\end{array}$ \\
\hline$\Delta h c p 1-2$ & $\begin{array}{l}\text { 5'-TGATAATCAAGGGCTCATTTCAAGTG- } \\
\text { GTTGTTCATCACAACCATCCATTGCATAT- } \\
\text { GAATATCCTCCTTA -3' }\end{array}$ \\
\hline gap $A-\mathrm{F}$ & 5'- CGTTAAAGGCGCTAACTTCG- 3' \\
\hline $\mathrm{R}$ & 5'-ACGGTGGTCATCAGACCTTC- 3' \\
\hline$f e d F-\mathrm{F}$ & 5' -CCGTTACTCTTGATTTCTTTGTTG- 3' \\
\hline $\mathrm{R}$ & 5' -GGCATTTGGGTAGTGTTTGTCTT -3' \\
\hline$f i m H-F$ & 5'- GGCTGCGATGTTTCTGCTC -3' \\
\hline $\mathrm{R}$ & 5'- CCCCAGGTTTTGGCTTTTC -3' \\
\hline$A I D A-\mathrm{F}$ & 5'- CAGTCTACCGCACAAGCAAAAC-3' \\
\hline $\mathrm{R}$ & 5'- CAGTCTACCGCACAAGCAAAAC-3' \\
\hline$f i c-\mathrm{F}$ & 5'- CAGCAAGCGGTGAAGTGAA -3' \\
\hline $\mathrm{R}$ & 5'-AAGCGTAGCCGCAGTAGCA -3' \\
\hline$s t x 2 e-\mathrm{F}$ & 5'- CGTCTGCTGTGCCTGTATGG -3' \\
\hline $\mathrm{R}$ & 5'- CTGGGCATAAATATCGTTGTCGT -3' \\
\hline
\end{tabular}

The wild type (F18ab), deletion mutant (F18ab $\Delta h c p 1)$ and complement strain (F18ab $\Delta$ hcpl/phcpl) were inoculated in biofilm induction medium as previously described (Yang et al., 2014; Zhou et al., 2014). The OD values of each well were recorded to measure the amount of biofilm production using a crystal violet staining method. Each strain was tested using six replicates, and the experiment was conducted in triplicate.

The strains were inoculated in LB medium and cultured overnight at $37{ }^{\circ} \mathrm{C}$. $1 \mu \mathrm{L}$ of each strain was transferred to the middle of semi-solid medium (1\% tryptone, $0.25 \%$ $\mathrm{NaCl}, 0.3 \%$ agar) respectively, and incubated at $37{ }^{\circ} \mathrm{C}$ for $16 \mathrm{~h}$. Motility halos were measured as previously described (Duan et al., 2013).

\section{Adherence and invasion assay towards IPEC-J2}

RPMI 1640 and Ham's F12 medium (1:1) containing $10 \%$ newborn bovine serum were used for IPEC-J2. Cells were cultured and transferred into 96 well plate. Briefly, $10^{7} \mathrm{CFU}$ of bacteria was added to each well of a 96-well tissue culture plate with a monolayer of approximately $10^{5}$. After incubation for $1 \mathrm{~h}$, cells were washed with PBS ( $\mathrm{pH}$ 7.2) for 3 times, and then lysed with $0.5 \%$ Triton X-100 for $20 \mathrm{~min}$. Solutions were diluted to 1:10 in PBS, and were spread on the LB plate for bacterial counting (Yang et al., 2021).

Invasion assays were performed as previously described (Yang et al., 2013). The monolayer cells were washed with PBS buffer ( $\mathrm{pH}$ 7.2) for 3 times, and the strains were added with MOI at 1:100 respectively. After incubation for $2 \mathrm{~h}$, cells were washed with PBS ( $\mathrm{pH} 7.2$ ) for 3 times, and gentamicin $(50 \mu \mathrm{g} / \mathrm{mL})$ was added. After additional $2 \mathrm{~h}$ incubation, $0.5 \%$ Triton $\mathrm{X}-100$ was used for cell lysis. The number of bacteria that invaded IPEC-J2 cells was enumerated. DH5 $\alpha$ was used as negative control.

\section{Bacterial colonization assay in mice intestine}

12 ICR mice (4-week-old) were divided into 3 groups: Wild type group, deletion strain group and complement strain group. $48 \mathrm{~h}$ before challenge, $5 \mathrm{~g} / \mathrm{L}$ streptomycin was added to drinking water to eradicate the normal resident flora in the intestine. Fructose (6.7\%) was added to increase the amount of drinking water. Cimetidine $(50 \mathrm{mg} / \mathrm{kg})$ was administered intraperitoneally $3 \mathrm{~h}$ before challenge to reduce gastric acid secretion (van der Velden et al., 1998). $2 \times 10^{8} \mathrm{CFU}$ bacteria were injected intragastrically into mice. Feces pellets were collected every day after challenge. After dissolving with PBS, 10fold dilution series were plated on MacConkey agar plates to determine the number of CFU of $E$. coli. Experiment lasted for 5 days.

\section{Vero cell cytotoxicity assay}

Wild type (F18ab), deletion strain (F18ab $\Delta h c p 1)$,

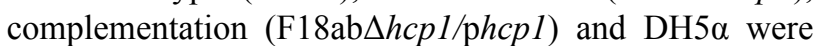
inoculated in LB medium at $37^{\circ} \mathrm{C}$. Strains were cultured to an $\mathrm{OD}_{600}$ of 0.3 , then mitomycin $\mathrm{C}(0.25 \mu \mathrm{g} / \mathrm{mL})$ was added into each tube. After $12 \mathrm{~h}$ induction, culture supernatants were filtered through $0.22 \mu \mathrm{m}$ filters. $100 \mu \mathrm{L}$ supernatants was added to the Vero cells and incubated for $20 \mathrm{~h}$, with DMEM as negative control (Yang et al., 2014). According to the instructions of Cell Proliferation Reagent WST-1 Kit, $100 \mu \mathrm{L}$ supernatants were added into Vero cells followed by $25 \mu \mathrm{L}$ Cell Proliferation WST-1 Reagent for $4 \mathrm{~h}$ incubation. $\mathrm{OD}_{450}$ was measured.

RNA extraction and real-time fluorescence quantitative $P C R$

Each strain was growing to $\mathrm{OD}_{600}$ at 2.0. Total RNA of each strain were extracted by TRIzol method (Zhou et al., 2014). The primers used for $f l i C$, fimH, fedf, AIDA and stx $2 e$ genes were listed in Table II. gap $A$ gene was used as housekeeper gene. SYBR®Premix Ex Taq II (Takara, Shiga, Japan) and ABI 7500 Real Time System (Applied Biosystems) were employed for subsequent experiments. 
The obtained data were processed based on the $2^{-\Delta \Delta} \mathrm{Ct}$ method.

\section{Statistical analyses}

All statistical analyses were performed using SPSS 15.0 software (SPSS Inc., Chicago, IL, USA). Differences in data were analyzed with t-test.

\section{RESULTS}

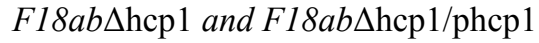

The $h c p 1$ deletion strain F18ab $\Delta h c p 1$ was constructed from its wild type F18ab 107/86 by using $\lambda$ Red-based recombination system. The complete reading frame of hcpl was amplified by PCR, inserted into pBR322 plasmid and transformed into F18ab $\Delta h c p 1$. The complement strain F18ab $\Delta h c p 1 /$ phcpl was also successfully constructed. F18ab $\Delta h c p 1$ was verified verified by combined PCR and sequencing data. The results of growth curve and biofilm formation assay showed that there was no significant difference between F18ab, F18ab $\Delta h c p 1$ and F18ab $\Delta h c p 1 /$ phcpl (Fig. 1).
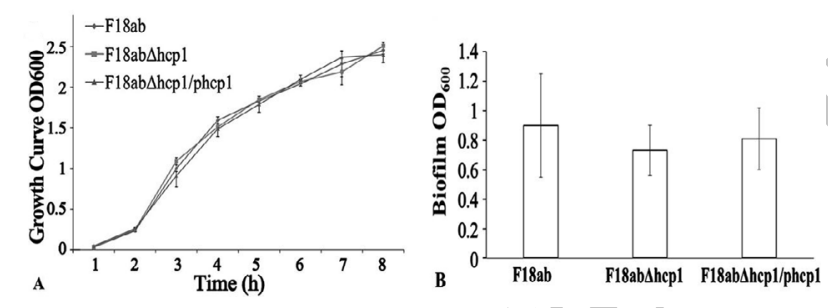

Fig. 1. Results of growth curve (A) and motility assay (B). Notes: A, there was no significant difference in growth rate among the three strains. B, there was no significant difference in biofilm formation ability among the three strains.

\section{Results of bacterial adhesion and colonization assays}

The results showed that the diameter of the motion circle of F $18 \mathrm{ab} \Delta h c p 1$ decreased by about $18.8 \%$, compared with the wild type. The motility of F18ab $\Delta h c p 1 / \mathrm{p} h c p 1$ was slightly improved (Fig. 2A), compared with F18ab $\Delta h c p 1$. In the adhesion assay, compared with wild type, the adherence ability of F $18 \mathrm{ab} \Delta h c p 1$ to IPEC-J 2 decreased by about $40 \%$ (Fig. 2B).

The invasion ability of each strain was analyzed. Extracellular bacteria which failed to invade IPEC-J2 were killed by antibiotics, and cells were lysed by $0.5 \%$ Triton $\mathrm{X}-100$. The intracellular bacteria were released for plate counting. Compared with wild type, the invasion ability of $\mathrm{F} 18 \mathrm{ab} \Delta h c p 1$ decreased by $28.3 \%$, and invasion of F18ab $\Delta$ hcp 1/phcpl was recovered (Fig. 2C).
MacConkey plates counting assay (Fig. 2D) showed that, after the challenge, the bacterial shedding of wild type strain and F18ab $\Delta h c p 1 / \mathrm{p} h c p 1$ displayed a gradual upward trend. The excretion of F18ab $\Delta h c p 1$ gradually decreased. The knockout of hcp 1 gene may block the secretion pathway of T6SS and hindered the secretion of protein molecules related to the process of adhesion and colonization.
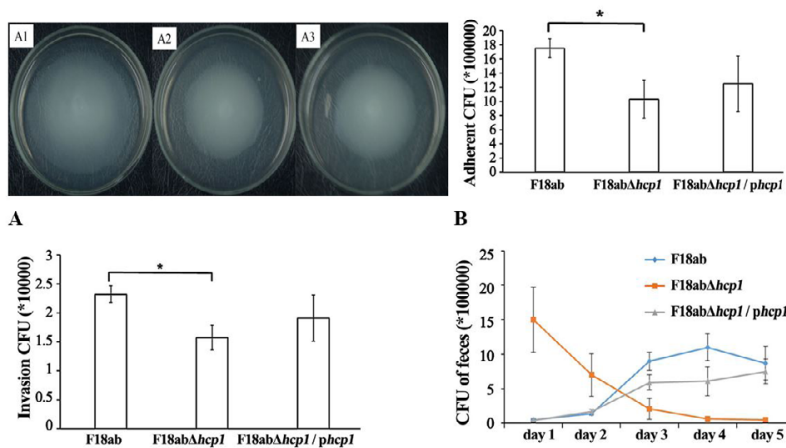

C

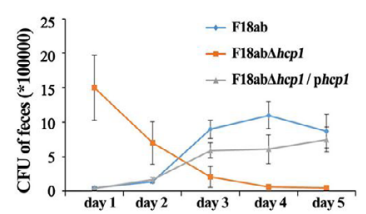

Fig. 2. The motility, adherence and colonization assays of bacterial. A, Flagella related motility assays. A1: F18ab; A2: F18ab $\Delta h c p 1$; A3: F18ab $\Delta h c p 1 / \mathrm{p} h c p 1$. B, Adherence ability towards IPEC-J2 cell line. C, Invasion ability towards IPEC-J2 cell line. D, Intestinal colonization test. * Significant difference, $\mathrm{p}<0.05$.

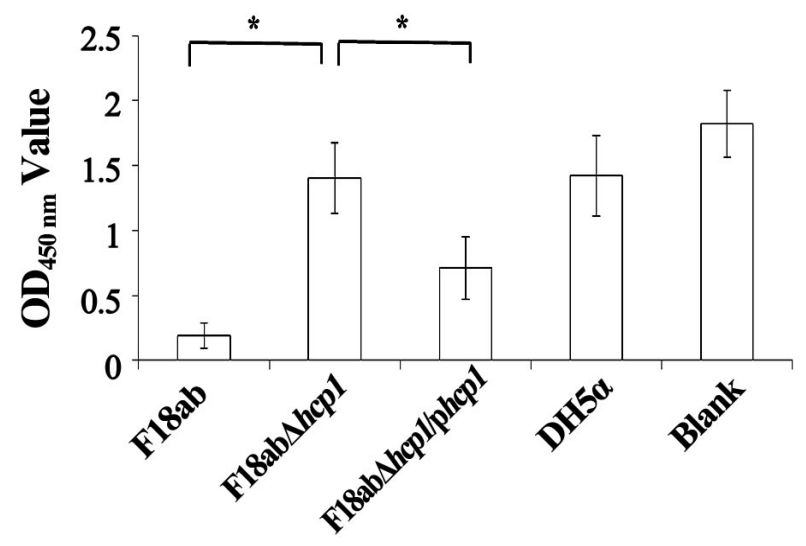

Fig. 3. Vero cell cytotoxicity assay.

* Significant difference, $\mathrm{p}<0.05$.

\section{Cytotoxicity assay}

The results showed that, in hcpl deletion strain group, the number of surviving cells is seven times that of wild type group (Fig. 3), which proved that the deletion of hcpl inhibited the synthesis or secretion of Stx2e. The cytotoxicity of the deletion strain is similar to that of the negative control group. The cytotoxicity of F18ab $\Delta h c p 1 /$ phcpl was significantly higher than that of deletion strain. 
The transcription levels of virulence genes

Total RNA of F18ab, F18ab $\Delta h c p 1$ and F18ab $\Delta h c p 1 /$ phcpl were extracted, respectively, and were reverse transcribed into cDNA. Housekeeping gene gap $A$ was used in this experiment. The expression levels of five important virulence factors $f i m H, f e d F, f l i C, A I D A$ and stx $2 e$ were detected. As shown in Figure 4, the transcription level of fliC decreased by about $28 \%$. The expression of $f i m H$ (type I fimbriae) decreased by $31 \%$, and there was no significant difference in expression of $f e d F, A I D A$ and stx $2 e$ (Fig. 4).

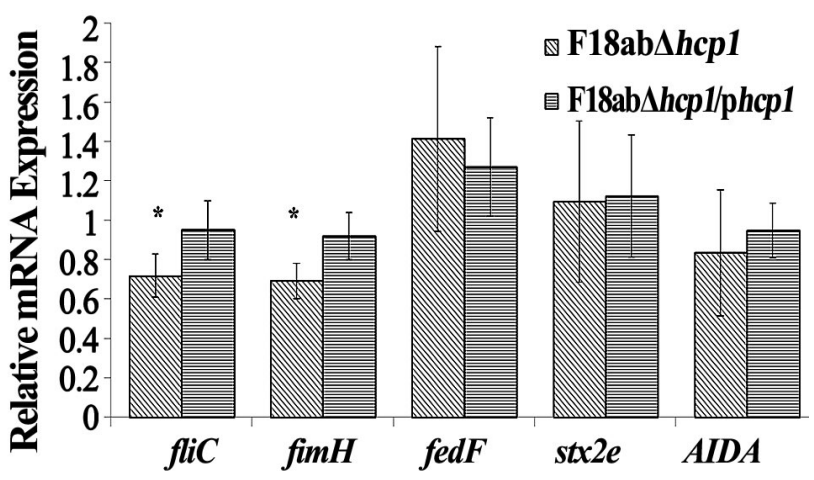

Fig. 4. Transcriptional levels of virulence related genes. $*$ : The gene transcriptional levels compared with F18ab, $P<0.05$

\section{DISCUSSION}

T6SS plays an important role in the pathogenic process of bacterial infection. About $25 \%$ of Gram-negative bacteria have the genes encoding T6SS. HCP family plays an important role in the interaction between bacteria and host cells in T6SS. The HCP protein is a landmark component of T6SS. Previous studies have shown that 2-3 $h c p$ gene clusters ( $h c p 1, h c p 2$ and $h c p 3$ ) have been found in meningitis-causing $E$. coli, avian pathogenic $E$. coli and porcine extraintestinal pathogenic $E$. coli (Ding et al., 2018; Song et al., 2020; Hu et al., 2021). Three hcp gene clusters exhibit different functions. However, the role of T6SS and HCP in the pathogenesis of F18ab STEC has not been well elucidated.

In this study, the growth trend of wild type, deletion mutant, and complement strains is the same. There is no significant difference in the lag phase, logarithmic growth phase, stable phase and decay phase, indicating that Hcp1 did not affect the growth of F18 E. coli (Fig. 1A).

STEC mediates the adherence of bacteria to host cells through F18 fimbriae, flagella and other adhesins (Da et al., 2001). After adherence, bacteria would invade into host cells or forms biofilm to colonize in host, and then releases Stx2e and other toxins, causing edema lesions. In this study, the related characteristics of bacterial adhesins influenced by $h c p l$ were investigated, and the transcription levels of major adhesins were detected by fluorescence quantitative PCR. F18ab E. coli mainly relies on its flagella to achieve its motor function. Most flagella subunits are assembled outside the plasma membrane, thus the protein molecules used for assembly need to be synthesized in the cytoplasm and then transported to the final assembly position through the inner membrane and outer membrane. Flagella not only mediate bacterial motility, but also acts as an important adhesin to mediate the adherence process between bacteria and host cells. The results showed that the motility of hcpl deletion strain decreased by $18.8 \%$ (Fig. 2A). T6SS may be involved in the transport process of flagella subunit protein, or the secretion of other cofactors involved in the assembly process of flagella subunit protein. The deletion of hcpl leads to the decrease of assembly efficiency of flagellum, resulting in the weakening of bacterial motility. In this study, it was found that the adherence ability of $\Delta h c p 1$ deletion strain was reduced by $40 \%$ (Fig. $2 \mathrm{~B}$ ), and its invasion ability decreased by $28.3 \%$ (Fig. 2C). The transcription levels of several main adhesion factor genes showed that the expression of flagella $\mathrm{fliC}$, type I fimbriae fim $H$ decreased by 28 and $31 \%$, respectively (Fig. 4). The results indicated that $h c p l$ is related to the expression of type I fimbriae and flagella in F18 STEC strain, and deletion of hcpl can inhibit the motility, adherence and invasion of F18 STEC.

Biofilm is a bacterial morphological change for adaptability, which can enhance the bacterial resistance to the external environment. Biofilm can greatly improve bacterial colonization in the host (Duan et al., 2012). After hcpl deletion, there was no significant difference in biofilm formation ability between STEC deletion strain and wild strain (Fig. 1B), which proved that Hcp may not be involved in biofilm formation.

F18 STEC attached to porcine intestinal epithelial cells through adhesins, and then colonizes and secreted Stx2e. Through subunit B, Stx2e binds to Gb5 receptor of intestinal epithelium and can be ingested by the intestinal epithelial cells through endocytosis. Stx2e can induce apoptosis through subunit $\mathrm{A}$, influence the vascular permeability, causes osmotic pressure disorder, and finally leads to edema (Niewerth et al., 2001). The expression level of Stx2e toxin gene in deletion strain F18ab $\Delta h c p 1$ did not change (Fig. 4), but the toxicity to Vero cells decreased significantly (Fig. 3). The numbers of surviving cells in wild and complement strain group were less than hcpl deletion strain, indicating that $\mathrm{Stx} 2 \mathrm{e}$ proteins in the supernatant of deletion strain was reduced. T6SS may be an important secretory pathway for Stx2e. The difference in cytotoxicity between the hcpldeletion strain and the 
wild type did not come from the difference in the synthesis and expression of toxin, but from the release and secretion process.

\section{CONCLUSION}

In conclusion, T6SS hcpl affects flagella and type I fimbriae in F18 STEC. Deletion of hcpl suppress bacterial motility, adherence, invasion ability, and colonization in mice. Moreover, it is closely related to the release and secretion process of Stx2e, and is deeply involved in bacterial cytotoxicity. The exploration of the effect of hcpl laid a foundation for further clarifying the complex function of T6SS system in F18 STEC.

\section{ACKNOWLEDGMENTS}

This study was supported by grants from the Chinese National Science Foundation Grants (Nos. 31972708, $31502075,31873010,31672579), 13^{\text {th }}$ Five-Year National Key Development Program (2016YFD0501000), the Priority Academic Program Development of Jiangsu Higher Education Institutions.

\section{Ethical compliance}

The protocols for animal experiments were approved by the Jiangsu Administrative Committee for Laboratory Animals (approval number: SYXK-SU-2007-0005), and complied with the guidelines of Jiangsu laboratory animal welfare and ethics of Jiangsu Administrative Committee of Laboratory Animals.

\section{Statement of conflict of interest}

The authors have declared no conflict of interest.

\section{REFERENCES}

Aubert, D.F., Flannagan, R.S. and Valvano, M.A., 2008. A novel sensor kinase-response regulator hybrid controls biofilm formation and type VI secretion system activity in Burkholderia cenocepacia. Infect. Immun., 76: 1979-1991. https://doi.org/10.1128/ IAI.01338-07

Da, S.A., Valadares, G.F., Penatti, M.P., Brito, B.G. and Da, S.L.D., 2001. Escherichia coli strains from edema disease: O serogroups, and genes for Shiga toxin, enterotoxins, and F18 fimbriae. Vet. Microbiol., 80: 227-233. https://doi.org/10.1016/ S0378-1135(01)00316-9

Datsenko, K.A. and Wanner, B.L., 2000. One-step inactivation of chromosomal genes in Escherichia coli K-12 using PCR products. Proc. natl. Acad. Sci.
U. S. A., 97: 6640-6645. https://doi.org/10.1073/ pnas. 120163297

Ding, X., Zhang, Q., Wang, H., Quan, G., Zhang, D., Ren, W., Liao, Y., Xia, P. and Zhu, G., 2018. The different roles of $h c p 1$ and $h c p 2$ of the type VI secretion system in Escherichia coli strain CE129. J. Basic Microbiol., 58: 938-946. https://doi. org/10.1002/jobm.201800156

Duan, Q., Zhou, M., Zhu, X., Bao, W., Wu, S., Ruan, X., Zhang, W., Yang, Y., Zhu, J. and Zhu, G., 2012. The flagella of F18ab Escherichia coli are a virulence factor that contributes to infection in a IPEC-J2 cell model in vitro. Vet. Microbiol., 160: 132-140. https://doi.org/10.1016/j.vetmic.2012.05.015

Duan, Q., Zhou, M., Zhu, X., Yang, Y., Zhu, J., Bao, W., Wu, S., Ruan, X., Zhang, W. and Zhu, G., 2013. Flagella from $\mathrm{F} 18+$ Escherichia coli play a role in adhesion to pig epithelial cell lines. Microbiol. Pathog., 55: 32-38. https://doi.org/10.1016/j. micpath.2012.09.010

Filloux, A., Hachani, A. and Bleves, S., 2008. The bacterial type VI secretion machine: Yet another player for protein transport across membranes. Microbiology, 154: 1570-1583. https://doi. org/10.1099/mic.0.2008/016840-0

Hood, R.D., Singh, P., Hsu, F., Güvener, T., Carl, M.A., Trinidad, R.R.S., Silverman, J.M., Ohlson, B.B., Hicks, K.G., Plemel, R.L., Li, M., Schwarz, S., Wang, W.Y., Merz, A.J., Goodlett, D.R. and Mougous, J.D., 2010. A type VI secretion system of Pseudomonas aeruginosa targets a toxin to bacteria. Cell Host Microbe., 7: 25-37. https://doi. org/10.1016/j.chom.2009.12.007

Hu, L., Yu, F., Liu, M., Chen, J., Zong, B., Zhang, Y., Chen, T., Wang, C., Zhang, T., Zhang, J., Zhu, Y., Wang, X., Chen, H. and Tan, C., 2021. RcsBdependent regulation of type VI secretion system in porcine extra-intestinal pathogenic Escherichia coli. Gene, 768: 145289. https://doi.org/10.1016/j. gene.2020.145289

Niewerth, U, Frey, A., Voss, T., Le Bouguenec, C., Baljer, G., Franke, S. and Schmidt, M.A., 2001. The AIDA autotransporter system is associated with F18 and stx2e in Escherichia coli isolates from pigs diagnosed with edema disease and postweaning diarrhea. Clin. Diagn. Lab. Immunol., 8: 143-149. https://doi.org/10.1128/CDLI.8.1.143-149.2001

Parsons, D.A. and Heffron, F., 2005. sciS, an icmF homolog in Salmonella enterica serovar Typhimurium, limits intracellular replication and decreases virulence. Infect. Immun., 73: 4338-4345. https://doi.org/10.1128/IAI.73.7.4338-4345.2005 
Peng, Y., Wang, X., Shou, J., Zong, B., Zhang, Y., Tan, J., Chen, J., Hu, L., Zhu, Y., Chen, H. and Tan, C., 2016. Roles of Hcp family proteins in the pathogenesis of the porcine extraintestinal pathogenic Escherichia coli type VI secretion system. Sci. Rep. U. K., 6: 26816. https://doi.org/10.1038/srep26816

Pukatzki, S., Ma, A.T., Revel, A.T., Sturtevant, D. and Mekalanos, J.J., 2007. Type VI secretion system translocates a phage tail spike-like protein into target cells where it cross-links actin. Proc. natl. Acad. Sci. U. S. A., 104: 15508-15513. https://doi. org/10.1073/pnas.0706532104

Pukatzki, S., McAuley, S.B. and Miyata, S.T., 2009. The type VI secretion system: Translocation of effectors and effector-domains. Curr. Opin. Microbiol., 12: 11-17. https://doi.org/10.1016/j.mib.2008.11.010

Shrivastava, S. and Mande, S.S., 2008. Identification and functional characterization of gene components of Type VI Secretion system in bacterial genomes. PLoS One, 3: e2955. https://doi.org/10.1371/ journal.pone.0002955

Song, X., Hou, M., Jiang, H., Shen, X., Xue, M., Shao, Y., Wang, L., He, Q., Zheng, L., Tu, J and K Qi, 2020. Hcp2a of type VI secretion system contributes to IL8 and IL1 $\beta$ expression of chicken tracheal epithelium by affecting APEC colonization. Res. Vet. Sci., 132: 279-284. https://doi.org/10.1016/j. rvsc.2020.07.007

Suarez, G., Sierra, J.C., Sha, J., Wang, S., Erova, T.E., Fadl, A.A., Foltz, S.M., Horneman, A.J. and Chopra, A.K., 2008. Molecular characterization of a functional type VI secretion system from a clinical isolate of Aeromonas hydrophila. Microb. Pathog., 44: 344-361. https://doi.org/10.1016/j. micpath.2007.10.005

van der Velden, A.W., Baumler, AJ, Tsolis, R.M. and Heffron, F., 1998. Multiple fimbrial adhesins are required for full virulence of Salmonella typhimurium in mice. Infect. Immun., 66: 28032808. https://doi.org/10.1128/IAI.66.6.28032808.1998

Williams, S.G., Varcoe, L.T., Attridge, S.R. and Manning, P.A., 1996. Vibrio cholerae Hcp, a secreted protein coregulated with HlyA. Infect. Immun., 64: 283-289. https://doi.org/10.1128/ iai.64.1.283-289.1996

Yahr, T.L., 2006. A critical new pathway for toxin secretion? New Engl. J. Med., 355: 1171-1172. https://doi.org/10.1056/NEJMcibr063931
Yang, Y., Yao, F., Zhou, M., Zhu, J., Zhang, X., Bao, W., Wu, S., Hardwidge, P.R. and Zhu, G., 2013. F18ab Escherichia coli flagella expression is regulated by acyl-homoserine lactone and contributes to bacterial virulence. Vet. Microbiol., 165: 378-383. https://doi.org/10.1016/j.vetmic.2013.04.020

Yang, Y., Zhang, X., Zhang, B., Zhou, M., Duan, Q., Li, Z., Zhang, X. and Zhu, G., 2021. Quorum sensing-1 signaling of N-hexanoyl-l-homoserine lactone contributes to virulence in avian pathogenic Escherichia coli. Arch. Microbiol., Accepted in press. https://doi.org/10.21203/rs.3.rs-674139/v1

Yang, Y., Zhou, M., Hardwidge, P.R., Cui, H. and Zhu, G., 2018. Isolation and characterization of $\mathrm{N}$-acyl homoserine lactone-producing bacteria from cattle rumen and swine intestines. Front. Cell Infect. MI, 8: 155 . https://doi.org/10.3389/fcimb.2018.00155

Yang, Y., Zhou, M., Hou, H., Zhu, J., Yao, F., Zhang, X., Zhu, X., Hardwidge, P.R. and Zhu, G., 2014. Quorum-sensing gene luxS regulates flagella expression and Shiga-like toxin production in F18ab Escherichia coli. Can. J. Microbiol, 60: 355-361. https://doi.org/10.1139/cjm-2014-0178

Yi, Z., Wang, D., Xin, S., Zhou, D., Li, T., Tian, M., Qi, J., Ding, C., S Wang, and Yu, S., 2019. The CpxR regulates type VI secretion system 2 expression and facilitates the interbacterial competition activity and virulence of avian pathogenic E. scherichia coli. Vet. Res., 50: 40. https://doi.org/10.1186/ s13567-019-0658-7

Zheng, J., Ho, B. and Mekalanos, J.J., 2011. Genetic analysis of anti-amoebae and anti-bacterial activities of the type VI secretion system in vibrio cholerae. PLoS One, 6: e23876. https://doi. org/10.1371/journal.pone.0023876

Zhou, M., Guo, Z., Yang, Y., Duan, Q., Zhang, Q., Yao, F., Zhu, J., Zhang, X., Hardwidge, P.R. and Zhu, G., 2014. Flagellin and F4 fimbriae have opposite effects on biofilm formation and quorum sensing in F4ac+ enterotoxigenic Escherichia coli. Vet. Microbiol., 168: 148-153. https://doi.org/10.1016/j. vetmic.2013.10.014

Zhou, Y., Tao, J., Yu, H., Ni, J., Zeng, L., Teng, Q., Kim, K.S., Zhao, G., Guo, X and Yao, Y., 2012. Hcp family proteins secreted via the type VI secretion system coordinately regulate Escherichia coli $\mathrm{K} 1$ interaction with human brain microvascular endothelial cells. Infect. Immun., 80: 1243-1251. https://doi.org/10.1128/IAI.05994-11 